\title{
PREVALENCE OF HYPERTENSION AMONG ADULT TYPE-2 DIABETES PATIENTS: A PRELIMINARY STUDY IN KUANTAN, PAHANG, MALAYSIA \\ Fa'iza Abdullah' $^{1}$, Tin Myo Han ${ }^{2}$, Mohd Basri Mat Nor ${ }^{3}$, Mohd Aznan MA ${ }^{1}$, Ida Zuriaty Ismail ${ }^{4}$
}

${ }^{1}$ Department of Family Medicine, Kulliyyah of Medicine, IIUM. ${ }^{2}$ Medical Statistics Unit, Kulliyyah of Dentistry, IIUM. ${ }^{3}$ Anaesthesiology \& Critical Care, Kulliyyah of Medicine, IIUM. ${ }^{4}$ Klinik Kesihatan Bandar Kuantan, Kuantan

Introduction: Hypertension (HPT) is the most common co-morbidity among type-2 diabetes mellitus (T2DM) patients which ominously increased their morbidity and mortality from cardiovascular diseases (CVD).

Objective: We aimed to describe the prevalence and control status of HPT, and also the glycemic control among T2DM patients in the primary care clinic.

Methodology: It was a study of 154 patients' record, aged $\geq 18$ years selected by random sampling. Of these, $47 \%$ were Malay, 45\% Chinese and 9\% Indian. The control status was compared between the last visit and the visit done one year previously.

Results: The prevalence of HPT among T2DM was 72.1\% and majority were women (60\%). Out of 82 T2DM patients aged $>60$ years, $80.5 \%$ were hypertensive. $67.2 \%$ of T2DM patients between age $40-60$ and $25 \%$ age $<40$ years were also hypertensive $(\mathrm{P}=0.003)$. $\mathrm{BP}$ control status were classified into controlled, uncontrolled, systolic and diastolic HPT. All patients were compared between the last visit and one year before, which reported 55.8\% vs. $33.1 \%, 14.9 \%$ vs. $51.9 \%, 20.1 \%$ vs. $10.4 \%$ and $9.1 \%$ vs. $4.5 \%$ respectively. There were significant rise in percentage of uncontrolled diastolic HPT (by 4.6\%) and uncontrolled systolic HPT (by 9.7\%), p $<0.001$, from the first visit. BP controlled status for aged group $>60$ years showed increments in systolic HPT and diastolic HPT which were significant $(\mathrm{p}<0.001)$. Regarding glycemic parameters, 71.4\% T2DM patients had poor controlled level of Hb1 Ac $(\geq 6.5)$ and only $20.1 \%$ remained controlled after one year $(p<0.001)$.

Conclusions: The study concluded high prevalence of HPT, increasing prevalence of systolic HPT and diastolic HPT in older age group as well as poor glycemic control among T2DM patient which mandate aggressive intervention.

\section{FACTORS AFFECTING ONLINE HEATH INFORMATION SEEKING BEHAVIOUR VIA FACEBOOK IN MALAYSIA: THE MALAYSIAN MEDICAL GAZETTE EXPERIENCE. Hidayah I. ${ }^{1}$, Dhesi B.R. ${ }^{2}$}

${ }^{1}$ Department of Basic Medical Sciences, Kulliyyah of Medicine , International Islamic University Malaysia, Jalan Sultan Ahmad Shah, Bandar Indera Mahkota, 25200 Kuantan, Pahang. ${ }^{2}$ Department of Community Medicine \& Public Health, Universiti Malaysia Sarawak, Jalan Datuk Musa, 94300 Kota Samarahan, Sarawak.

Introduction: The popularity of social media networks (SNSs) such as Facebook offer enormous potential for online health information sharing. The Malaysian Medical Gazette (MMG) is an online health education website (www.mmgazette.com) that incorporates SNSs plugins to increase reader engagement and propagate information.

Objective: This study aims to identify peak traffic times and factors that influence article engagement among MMG readers.

Methodology: The data was collected from Google Analytics (Malaysian Medical Gazette) and Facebook Share Analytics (4.2.5 Plug-in) over 22 months from 1st January 2014 to 31st October 2015.

Results: Out of 655 posts, 169 articles were found to have more than 1000 total counts. The most frequent monthly total page views were on weekdays ( $\mathrm{n}=20$ ), with 4 peak traffic times noted at 8 A.M.-9 A.M., 4 P.M.-5 P.M., 9 P.M.10 P.M. and 11 P.M.- 12 A.M. Bahasa Malaysia articles received the most total counts with 136 articles achieving more than 1000 total counts. Articles discussing medications (12.4\%) and women's health (10.7\%) were the most frequent categories of articles receiving more than 1000 total counts.

Conclusion: The results suggest that MMG readers engage with the website more on weekdays and during several peak times. Articles written in Bahasa Malaysia and those discussing medications and women's health are the most 
popular. Further studies on factors influencing health information sharing behaviour and cross disciplinary research involving healthcare professionals and social media marketers will increase understanding of effective use of SNSs for mass dissemination of information.

\section{KNOWLEDGE, ATTITUDE AND PRACTICE ON DENGUE AMONG ADULT POPULATION IN FELDA SUNGAI PANCHING TIMUR, KUANTAN, PAHANG.}

Karimah Hanim AA, Razman MR, Jamalludin AR, Nasreen EH, Htike Myat Phyu, SweSwe L, Hazifah P.

Department of Community Medicine, Kulliyyah of Medicine, International Islamic University Malaysia, Kuantan, Pahang, Malaysia

Introduction: With increasing number of dengue cases in Malaysia, it's of utmost importance that immediate action be taken to limit the epidemic. Since dengue control is a behavioural problem, the knowledge, attitude and practice in population needs to be studied in order to control the disease. Objective: The aim of this study is to assess knowledge, attitude and practice regarding dengue and its associated factors among adult residents of Felda Sungai Panching Timur (SPT), Kuantan, Pahang, 2014.

Methodology: A cross sectional study was carried out involving 265 adult respondents. A face to face interview questionnaire which was divided into 2 parts (Part A: Sociodemographic; Part B: Knowledge, Attitude and Practice) was used. Data was analysed using descriptive statistics, simple and multiple logistic regression.

Results: $53.2 \%$ of the respondents had good knowledge about dengue and it was found that the main source of information was from mass media (76.6\%). However, only 43.4\% were found to have good attitude towards dengue. Multiple Logistic Regression analysis showed that there was no association between sociodemographic characteristics with the level of knowledge and attitude towards dengue. There was also no association found between knowledge of dengue and the attitude of the respondents towards dengue. Descriptive analysis on the practice of dengue showed majority of the respondents who had possible breeding site for Aedes mosquitos (water container, drains/gutter roof/flower pots/ tires) in their compound practiced good habit in preventing the Aedes mosquitoes from breed.

Conclusion: Although knowledge and practice towards dengue is good, their attitude require improvement.

\section{Review}

\section{KNOWLEDGE, ATTITUDE AND PRACTICE of MEDICAL PERSONNEL ON SMOKING CESSATION GUIDELINES: A REVIEW ON ASSOCIATIONS AND QUESTIONNAIRES} ShaifulEhsan $\mathrm{SM}^{1}$, MohdAznan $M A^{1}$, Mohamad Haniki $N M^{2}$, Razman $\mathrm{MR}^{3}$, NA Jamani ${ }^{1}$

\footnotetext{
${ }^{1}$ Department of Family Medicine, Kulliyyah of Medicine, IIUM. ${ }^{2}$ Department of Pharmacy Practice, Kulliyyah of Pharmacy, IIUM. ${ }^{3}$ Department of Community Medicine, Kulliyyah of Medicine, IIUM
}

Number of active smokers in Malaysia is increasing despite availability of stop smoking clinics and smoking cessation medications. Other than smokers' level of motivation to quit smoking, competency of the healthcare professionals involved in providing smoking cessation intervention using evidence-based guidelines needs to considered. Hence, knowledge, attitude and practice (KAP) of the healthcare providers in relation to existing clinical practice guidelines on smoking cessation should be assessed. In this review, we look at the factors contributing to the KAP of medical personnel on the guidelines and also the previous available assessment tool, mainly in the form of a validated questionnaire, for the purpose of applying it to the context of the Malaysian healthcare providers. 